\title{
Fabrication of fine apatite/collagen composite for osteoconductive apical barrier material
}

\author{
Yoshihiro TAKENAKA, Mayumi IIJIMA*, Satoshi KAWANO, Yasumitsu AKITA, Takakazu YOSHIDA, \\ Yutaka DOI* and Ichiro SEKINE
}

Asahi University School of Dentistry, Endodontics, 1851-1, Hozumi, Hozumi-shi, Gifu 501-0296

*Asahi University School of Dentistry, Dental Materials Science, 1851-1, Hozumi, Hozumi-shi, Gifu 501-0296

\begin{abstract}
Aiming at creating an apical barrier material that promotes recovery of defects in the root canal, a composite of apatite and collagen was developed. To achieve this, reconstitution and cross-link of atelocollagen, and calcification of reconstituted collagen fibers, were conducted under controlled stirring at $37^{\circ} \mathrm{C}$. Deposits were identified as $\mathrm{CO}_{3}$-containing apatite and its crystallinity was comparable to that of bone apatite. After 20 hours of calcification, the composite contained apatite of about 60 wt $\%$. The composite and saline mixture had a pH of about 9. The mixture was easily set into a narrow space, such as the root canal, and was liquid permeable after being set into a root canal. The biological property of the composite was examined in vivo using the molar teeth of dogs. After 8 weeks, a thin layer of new bone-like tissue was formed along the inner wall of root canal. Without the composite paste, such a new bone-like tissue was not observed. Thus, the apatite/collagen composite showed potential as an apical barrier material with osteoconductivity.
\end{abstract}

Key-words: Apatite, Collagen, Composite, Osteoconduction, Apical ba mier material

[Received October 11, 2007; Accepted December 11, 2007] @2008 The Ceramic Society of Japan

1. Introduction

In the dental treatment of tooth root, there are some cases in which gutta-percha filling cannot be applied. In such cases, recovery through increment of surrounding hard tissue, i.e., cementum, can hardly be expected. Since rigid filling of root canal and expeditious blockade against periodontal tissue are required for a good recovery, biologically active material with a potential to induce hard tissue as an apical barrier has been explored. ${ }^{1-6)}$

Apatite-collagen $(\mathrm{Ap} / \mathrm{col})$ composite has compositional benefits to restoring the structure and biological functions of damaged bone, because both apatite and collagen are primary components of bone. ${ }^{7), 8)}$ In surgical treatment, collagen by itself has been used in wound dressing and adhesives in clinics owing to its biological functions. ${ }^{9)-11)}$ In particular, atelocollagen has a great deal of importance in clinical usage because of a lack of antigenicity. ${ }^{12)}$ Hydroxyapatite (HAp), the major inorganic component of bone and tooth, has a variety of applications as biomaterials owing to its excellent bioactivity and osteoconductivity. ${ }^{13)-17)}$

The purpose of this study was to fabricate a composite of apatite and atelocollagen with fine structure, which promotes recovery of defects at the apical region of the root canal. To achieve this, the fabrication method used in our previous study ${ }^{18), 19)}$ was slightly modified, i.e., all the processes were conducted under controlled stirring. The property and applicability of the resultant composite were examined.

2. Materials and methods

2.1 Fabrication of Ap/col composite

Atelocollagen $(5 \mathrm{ml})$ (Cellmatrix Type-I $\mathrm{A}^{\mathrm{TM}}$, Nitta Gela-

Correspondence to Mayumi IIJIMS; E-mail: iijima@dent.asahiu.ac.jp tin) was reconstructed with the addition of an equivalent amount of $200 \mathrm{mM}$ triethanolamine hydrochloride buffer solution $(\mathrm{pH} 8.0)$ at $37^{\circ} \mathrm{C}$ for $24 \mathrm{~h}$. Reconstructed collagen was cross-linked in $0.3 \%$ dimethylsuberimidate dihydrochloride (Nacalai Tesque) solution $(7.5 \mathrm{ml}$ ) containing $0.04 \%$ alkaline phosphatase (Type I-s, Siguma) and 0.04\% eggyolk phosvitine (Siguma) at pH8.0 and $37^{\circ} \mathrm{C}$ for 6 days. ${ }^{18 \text { ) }}$ After cross-linking, the assembly was soaked in $0.04 \%$ alkaline phosphatase and $0.04 \%$ phosvitine solution $(5 \mathrm{ml})$ for $3 \mathrm{~h}$ It was then put into a $6 \mathrm{mM}$ calcium $\beta$-glycerophosphate $\left(10 \mathrm{ml}, 37^{\circ} \mathrm{C}\right)$ for $20 \mathrm{~h}$. All the reactions were carried out under stirring with a speed of $700 \mathrm{rpm}$, inverting the stirring direction every 5 seconds. In each change of solution, the sample was thoroughly washed with doubledistilled water by means of a tube-mixer and centrifuged at $3000 \mathrm{rpm}$ for $10 \mathrm{~min}$. After the washing process was repeated twice, the sediment was lyophilized.

\subsection{Characterization of $\mathrm{Ap} / \mathrm{col}$ composite}

Products were characterized by means of an optic microscope, X-ray diffractometer (XRD, Rigaku), scanning electron microscope (SEM, Hitachi), fourier-transform infrared spectrometer (FT-IR, Shimadzu) and thermo gravimetric (TG) analyzer (Rigaku).

The Ap/col composite was mixed with saline to apply it to the defect at apical part of the tooth root. The composite to liquid (i.e., powder to liquid $(\mathrm{P} / \mathrm{L})$ ) ratio was explored to obtain a mixture suitable to set into a narrow space, such as the root canal of a tooth. The $\mathrm{pH}$ of the mixture was measured using a universal pH indicator (Toyo Roshi). A liquid permeation test was performed using human molar teeth, which were removed for some reasons. A mixture of Ap/col composite and saline, gutta-percha and composite resin were set in a root canal as indicated by A, B and C in Fig. 1. After 48 hours of soaking in Indian -ink, the height of the stained 


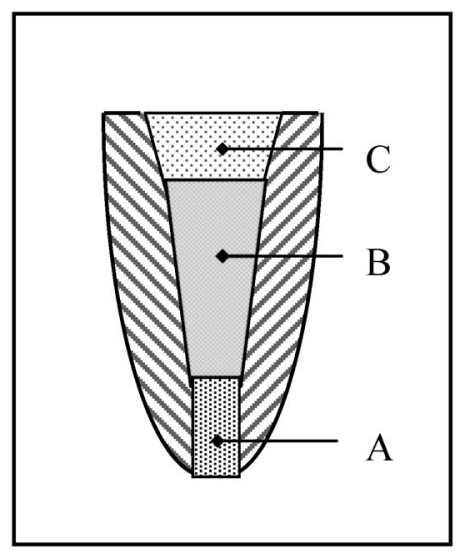

Fig. 1. Method of root canal filling employed in this study. A: Ap/ col composite; B: gutta-percha; C: composite resin. In the control experiment, the Ap/col composite was not filled.

region in the $\mathrm{Ap} /$ col composite was measured.

\subsection{In vivo Application of $\mathrm{Ap} / \mathrm{col}$ composite}

An animal study (approved by the Animal Care and Use Committee of Asahi University No. 06-001) was conducted using third and fourth lower molar teeth of six adult dogs $(8-10.5 \mathrm{~kg})$. A defect was made at the apical part of each root. Aliquot of $\mathrm{Ap} / \mathrm{col}$ mixture with saline was set to the apical of the root at a height of about $2 \mathrm{~mm}$ from the bottom (A in Fig. 1). The remaining part of the root was filled with gutta-percha point (B in Fig. 1) and the top was covered with composite resin (C in Fig. 1). Several parallel experiments were performed without the Ap/col mixture. After 8 weeks, each animal was sacrificed and the tooth with surrounding tissue was removed and fixed in 10\% neutral formaldehyde for 4 days. For a histological study, sample blocks were decalcified (K-CX, Falma) and dehydrated using a graded ethanol series (70-100\%) and transferred into paraffin. Longitudinal sections $(6 \mu \mathrm{m}$ in thickness $)$ were made and stained with hematoxylin and eosin (HE).

\section{Results and discussion}

The texture and property of lyophilized Ap/col composite after calcification was cotton-like under an optical microscope (Fig. 2a). The fine fibers assembled loosely and were unraveled. SEM observation indicated that the composite was composed of fine strings of collagen fibers, on which small granules deposited. The size of granules was around 50-100 nm (Fig. 2b). According to the TG analysis, the mineral content of the Ap/col composite was about $60 \mathrm{wt} \%$. When a similar reaction was carried out without stirring, a lump of composite was obtained and it took several days to deposit $60 \%$ wt of apatite. ${ }^{19)}$ Fine collagen fibers formed under stirring should have a large surface area, which offered lots of nucleation sites. ${ }^{20), 21)}$ Therefore, the calcification rate was promoted by stirring. Both the fibrous feature of collagen fibers and the size of apatite particles were unchanged during the calcification reaction. This could also be ascribed to the stirring method employed in this study. Apatite with $50-100 \mathrm{~nm}$ has been deposited on collagen fibers by another procedure. ${ }^{22}$ ) The morphology of the crystal was different from that of this study. In both studies,

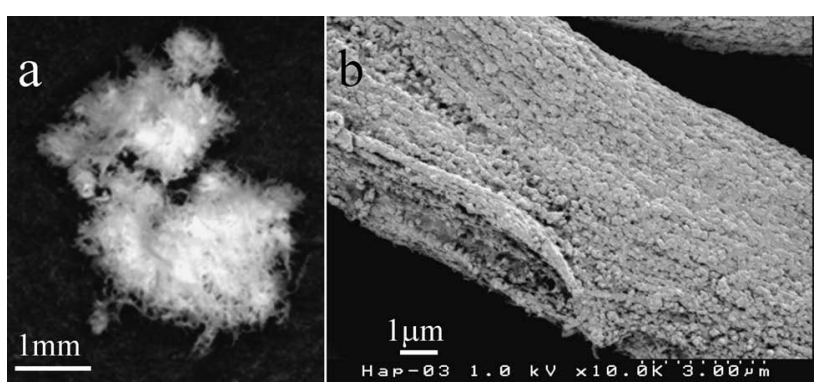

Fig. 2. (a) Optical microscopic and (b) SEM image of Ap/col composite after 1 day of calcification.

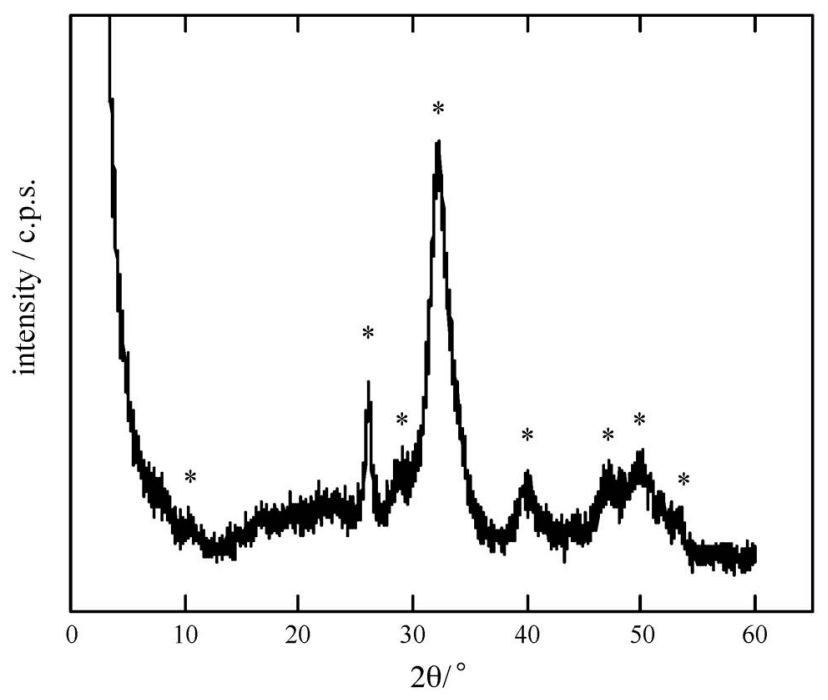

Fig. 3. X-ray diffraction patterns of Ap/col composite after 1day of calcification. *indicates diffraction peak of apatite.

calcification was carried out under stirring; nevertheless, crystals stayed on fibers. This suggested that apatite nucleated on collagen fiber with correlation, as proposed by $\mathrm{Katz}^{20)}$ and Jethi et al. ${ }^{21)}$

In the XRD pattern, there were several broad peaks, all of which were assigned to apatite $\left({ }^{*}\right.$ in Fig. 3). The crystallinity of apatite was low and the profile was similar to that of bone apatite. Figure 4 shows the FT-IR spectra of reconstituted collagen fiber before and after calcification (lower and upper, respectively in Fig. 4). Absorption bands of $\mathrm{CO}_{3}$ in apatite lattice were observed at 1545,1450 and 1410 $\mathrm{cm}^{-1}$, along with those of $\mathrm{PO}_{4}$ of apatite at 1020 and 870 $\mathrm{cm}^{-1}$. $^{23)-25)}$ It was possible that the $\mathrm{CO}_{3}$ band overlapped with the $\mathrm{PO}_{4}$ band at $870 \mathrm{~cm}^{-1}$. There are two types of $\mathrm{CO}_{3}$ apatite: OH-substitution, defined as Type-A, shows IR bands at around 1450, 1545 and $880 \mathrm{~cm}^{-1}$; and $\mathrm{PO}_{4}$-substitution, defined as Type-B, at around 1410, 1455 and $875 \mathrm{~cm}^{-1}$. Therefore, the mineral phase was identified as $\mathrm{CO}_{3}$-containing-apatite in which $\mathrm{CO}_{3}$ substituted for both $\mathrm{OH}$ and $\mathrm{PO}_{4}$, i.e., a mixture of Type-A and Type-B.

The powder to liquid $(\mathrm{P} / \mathrm{L})$ ratio of 1.2 yielded a homogenous paste-like mixture, which was suitable to set into a narrow space such as a root canal and to maintain it within the root during a certain period. When the $\mathrm{P} / \mathrm{L}$ ratio 


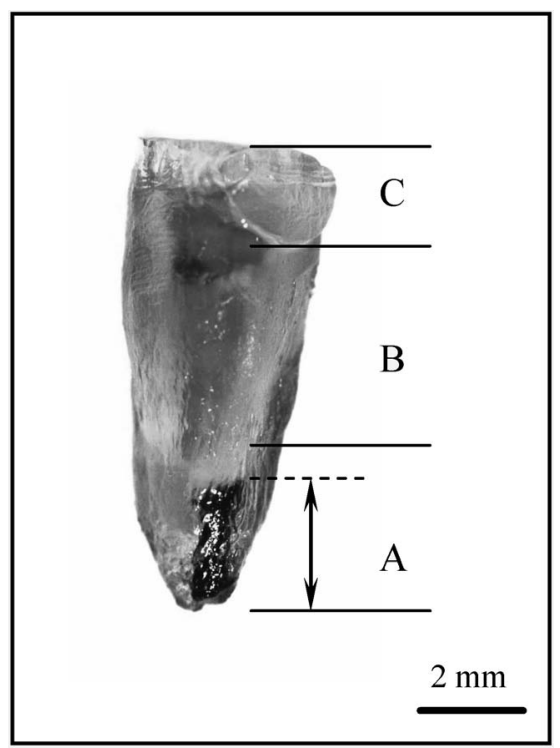

Fig. 4. Tooth root after $48 \mathrm{~h}$ of liquid permeation test. Ap/col composite (A), gutta-percha (B) and composite resin (C) were set in a root canal as shown in Fig. 1. Indian-ink permeated the region in the $\mathrm{Ap} / \mathrm{col}$ composite is indicated as by the arrow.

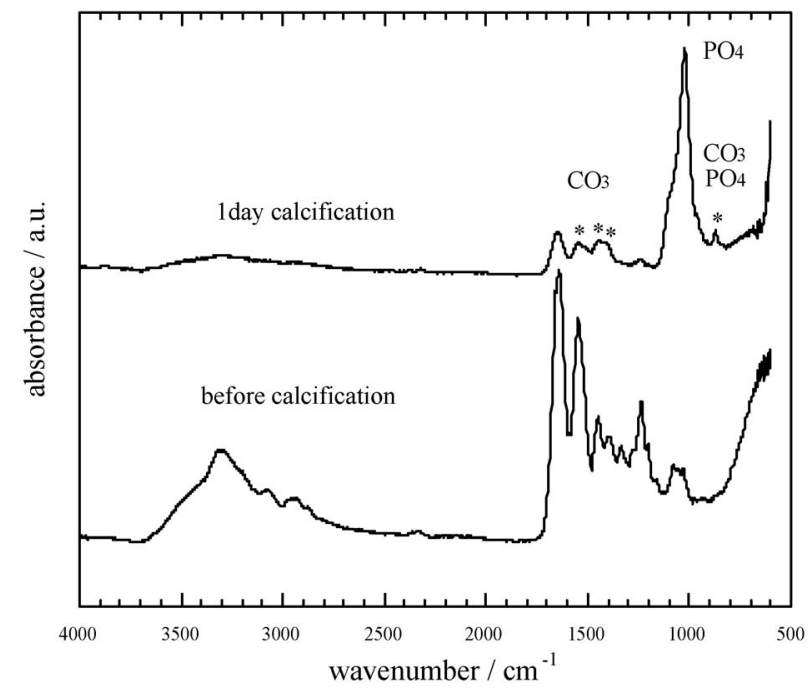

Fig. 5. FT-IR spectrum of reconstituted collagen before calcification and $\mathrm{Ap} / \mathrm{col}$ composite after 1day of calcification. Absorption bands of $\mathrm{CO}_{3}(*)$ and $\mathrm{PO}_{4}$ are indicated.

was lower than 1.0 , the mixture was too powder rich to make a homogeneous mixture. At a $\mathrm{P} / \mathrm{L}$ higher than 1.4 , the consistency was too large to maintain its shape. Such a soft mixture was supposed to flow out from the root and was inappropriate as an apical barrier material. Therefore, a $\mathrm{P} / \mathrm{L}$ ratio of 1.2 was used in the animal experiment. The $\mathrm{pH}$ of the mixture was about 9 . This should give slight pungency toward the surrounding tissue, as proved by the following histological analysis.

Figure 5 shows a tooth root after liquid permeation test. After $48 \mathrm{~h}$ of soaking in Indian-ink, the ink permeated into the Ap/col composite at a height of about $3 / 4$ of the compo-

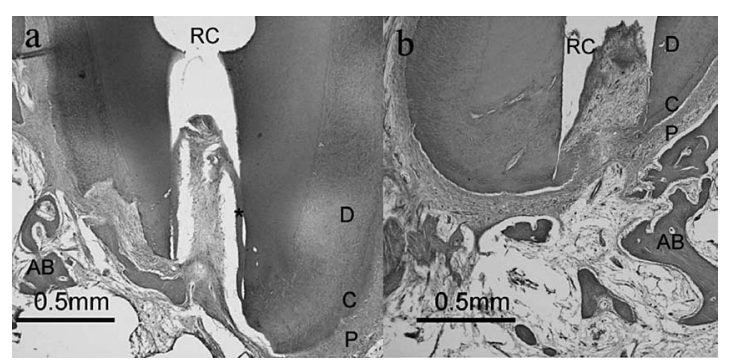

Fig. 6. HE stained section of dog molar tooth root (a) with and (b) without Ap/col filling after 8 weeks of operation. * : newly formed hard tissue; AB: alveolar bone; C: cementum; D: dentin, P: periodontium, RC: root canal. In (a), the layer of newly formed hard tissue constructed a barrier against periodontal tissue. In (b), apex was sealed by fibrous tissue (stricture of root canal).

site from the bottom, as indicated by arrow. The height of penetration was in the range from $1 / 4$ to $3 / 4$ of the composite from the bottom. This indicated that the Ap/col mixture had liquid permeability even when it was crammed into a root canal. Furthermore, it was suggested that the rate of penetration changed depending on the tightness of the Ap/ col composite. In other words, the permeation of body fluid could be controlled by the tightness of the composite.

Histological examination showed no indication of toxicity of the Ap/col composite nor was there inflammation when the composite was applied. As shown by Fig. 6a, a thin layer of newly formed bone-like tissue, which was lightly stained by HE, was observed. In the root canal, newly formed hard tissue was observed along the inner wall, which formed a barrier against periodontal tissues at a height of about one third from the bottom. On the other hand, without the composite, such a new hard tissue was not observed nor was it increment of cementum (Fig. 6b). The apical part of the root was covered with fibrous tissue instead of cementum, indicating stricture of the root canal. This suggested that the formation of the new hard tissue layer was conducted by the Ap/col composite.

The blockade against periodontal tissue performed by the layer of newly formed hard tissue (* in Fig. 6a) could be tighter than that performed by soft tissue ( $\mathrm{P}$ in Fig.6b). Therefore, recovery of the defect could be promoted owing to this layer. Since the Ap/col mixture had liquid permeability even when it was crammed into a root canal, the body fluid and blood could penetrate the mixture soon after operation. This could be a trigger of hard tissue formation. Osteoconductivitiy of apatite and the Ap/col composite has been proven ${ }^{13)-17), 26)}$ and is widely accepted nowadays. Thus, it was suggested that the layer of new hard tissue was formed under the influence of $\mathrm{Ap} / \mathrm{col}$ composite.

\section{Conclusion}

In conclusion, controlled stirring during the reaction was effective to fabricate $\mathrm{Ap} / \mathrm{col}$ composite with fine collagen fiber, on which $\mathrm{CO}_{3}$ containing apatite crystals with about $50-100 \mathrm{~nm}$ in size deposited. The composite contained about $60 \mathrm{wt} \%$ apatite after 1-day-calcification at $37^{\circ} \mathrm{C}$. A mixture of composite and saline with a $\mathrm{P} / \mathrm{L}$ ratio of $1.2 \mathrm{had}$ a $\mathrm{pH}$ of 9 and had liquid permeability even when it was crammed into a root canal. When the mixture was applied to the root canal with an apical defect of a dog molar tooth, a thin layer of 
bone-like tissue that constructed a barrier against surrounding tissue was formed after 8 weeks. Such a new bone-like tissue was not observed without the composite application. Thus, it was concluded that $\mathrm{Ap} / \mathrm{col}$ composite obtained by this method has high potential as an osteoconductive apical barrier material.

\section{References}

1) L. Tronstand, Oral Surg., 45, 297-304 (1978).

2) K. Safavi, P. Horsted, E. A. Pascon and K. Langeland, $J$. Enodon., 11, 18-24 (1985).

3) G. R. Hartwell and M. C. Marshal, J. Endodon., 19, 357-361 (1993).

4) T. Yoshida, T. Ito, S. Saotoh and I. Sekine, The Amer. Assoc. Endod., 24(9), 581-586 (1998).

5) A. L. Heller, I. F. Koenigs, D. J. Brilliant, C. R. Melfi and D. T. Driskell, J. Endod., 1(3), 95-101 (1975).

6) T. Yoshida, J. Gifu. Dent. Soc., 14, 309-328 (1987) [in Japanese]

7) W. F. Neuman and M. W. Neuman, Chem. Rev., 53, 1- 45 (1953).

8) R. A. Robinson, J. Bone Joint Surg., 34A, 389-434 (1956).

9) R. L. Ehrmann and G. O. Gey, J. Natl. Cancer Inst., 16, 1375-1403 (1956).

10) H. K. Kleinman, R. J. Klebe and G. R. Martin, J. Cell Biol., 88, 473-485 (1981).

11) S. Shoshan and S. Finkelstein, J. Surg. Res., 10, 485-491 (1960).

12) F. O. Schmitt, L. Levine, M. P. Drake, A. L. Rubin, D. Pfahl and P. F. Davison, Proc. Natl. Acad. Sci. USA, 51, 493-497
(1964).

13) H. Aoki, "Science and medical application of hydroxyapatite", Takayama Press System Center Co. Inc., Tokyo (1991) pp. 137-163.

14) J. L. Drummond, "Biomaterials in Reconstructive Surgery", Mosby and Co., St. Louis (1983).

15) Y. Doi, T. Horiguchi, Y. Moriwaki, H. Kitago, T. Kajimoto and Y. Iwayama, J. Biomed. Mater. Res., 31, 43-49 (1996).

16) Y. Akita, S. Kawano, Y. Takenaka, Y. Doi and I. Sekine, Jpn. J. Conserv. Dent., 48, 835-849 (2005) [in Japanese].

17) E. B. Kenny, V. Lekovic, J. C. Sa Ferreira, T. Han, B. Dimitrijevic and F. A.Carranz, Jr., J Periodontal., 57, 76-83 (1986).

18) M. Hasegawa, Y. Doi and A. Uchuda, J Bone Joint Surg. (Br) , 85B, 142-147 (2003).

19) B. D. Katthangen and H. Mittelmeier, Arch Orthop. Trauma Surg., 103, 291-302 (1984).

20) E. P. Katz, Biochim. Biophys. Acta., 194, 121-129 (1969).

21) R. K. Jethi, C. W. Inlow and C. L. Wadkins, Calcif. Tiss. Res., 6, 81-92 (1970).

22) M. Kikuchi, S. Itoh, S. Ichinose, K. Shinomiya and J. Tanaka, Biomaterials, 22, 1705-1711 (2001).

23) J. D. Termine and D. R. Lundy, Calcif. Tiss. Res., 15, 55-70 (1974).

24) J. C. Elliott, "Structure and Chemistry of the Apatites and Other Calcium Orthophosphates", Elsevier Co., London (1994).

25) M. E. Fleet and X. Liu, Biomaterials, 26, 7548-7554 (2005).

26) D. R. Mehlisch, A. S. Leider and W. E. Roberts, Oral Surg Oral Med Oral Pathol., 70, 685-692 (1990). 